\title{
Formação ao longo da vida e humanização: dialética para o potencialmente possível
}

\author{
Madson Pinto dos Santos* \\ Rosária Helena Ruiz Nakashima**
}

\section{Resumo}

O presente artigo pretendeu perceber a demanda existente em uma turma de Educação de Jovens e Adultos (EJA), lançar mão dos saberes e potencialidades dos interlocutores para resolução dialógica da situação-problema para um avançar dialético permanente, a fim de transformar realidades, com base nos seus sonhos, para uma vida mais digna. Para tanto, utilizamos métodos participativos como roda de conversa, círculo de cultura e mais especificamente a técnica brainstorm, que apontaram as temáticas trabalho como sendo um conflito e a escola como possibilidade de resolução, tecida pela cultura de paz, que requer estrutura democrática, realizando seus objetivos de maneira planejada e considerando o inédito viável. Palavras-chave: Formação ao longo da vida. Inédito viável. Humanização. Vantagens cumulativas.

\section{Lifelong training and humanization: dialetics for the potentially possible}

\section{Abstract}

This article intended to understand the demand existing in a group of Youth and Adult Education to use the knowledge and potential of the

* Mestre pela Universidade Federal do Tocantins - Campus Universitário de Araguaína - Programa de Pós-Graduação em Estudos de Cultura e Território (PPGCult).E-mail: madsonsantoscs@hotmail.com.

** Doutora em Educação pela Universidade de São Paulo (USP). Professora Adjunta do curso de Licenciatura em História. Docente do Programa de Pós-Graduação em Estudos de Cultura e Território (PPGCult) na Universidade Federal do Tocantins (UFT) - Campus Universitário de Araguaína. E-mail: rosaria@uft.edu.br. 
interlocutors for dialogical resolution of the problem situation for a permanent dialectical advance in order to transform realities, based on your dreams, for a more dignified life. We used participatory methods such as a conversation circle, a culture circle and, more specifically the brainstorm technique which pointed out the thematic work as a conflict and the school as a possibility of resolution, woven by the culture of peace, which requires democratic structure, so that their objectives are realized in a planned way, considering the unstested feasibility.

Keywords: Lifelong training. Untested feasibility. Humanization. Cumulative advantages.

\section{Formación permanente y humanización: dialéctica para lo potencialmente posible}

\section{Resumen}

Este artículo pretendía comprender la demanda existente en un grupo de Educación de Jóvenes y Adultos (EJA), aprovechar los conocimientos y potencialidades de los interlocutores para la resolución dialógica de la situación-problema para un avance dialéctico permanente, con el fin de transformar realidades, basado en tus sueños, para una vida más digna. Para ello, se utilizaron métodos participativos como el círculo de conversación, el círculo cultural y más específicamente la técnica de la lluvia de ideas, que apuntaba al trabajo temático como un conflicto y la escuela como una posibilidad de resolución, tejida por la cultura de paz, que requiere una política democrática. estructurar, cumpliendo sus objetivos de forma planificada y considerando factible lo inaudito.

Palabras clave: Formación permanente. Inédito viable. Humanización. Ventajas acumulativas.

\section{Introdução}

O presente artigo é resultado de uma pesquisa de mestrado, aprovada pelo comitê de ética ${ }^{1}$ e realizada, em 2019, com uma turma de Educação de Jovens e Adultos (EJA) composta por 11 alunos e sua professora, de uma escola pública municipal, em Araguaína, Tocantins. Sabendo se tratar da EJA, constituída de alunos

Aprovação do Conselho de Ética da Fundação Universidade Federal do Tocantins, Plataforma Brasil, sob o parecer 3.579.777, com observação de se tratar de uma pesquisa relevante para a EJA. 
geralmente expostos a situações de vulnerabilidade, a presente pesquisa lançou mão de metodologia participativa, promotora já em seu processo de compreensão da realidade em questão e de meios de intervenção e transformação de tal contexto.

Nesse sentido, inicialmente, realizamos uma roda de conversa para saber os motivos de terem interrompido os estudos quando mais jovens; a realidade atual em que se encontram; e os sonhos que aspiram. Em seguida, através de círculo de cultura, sintetizamos as discussões em temas geradores a saber: trabalho, escola e paz. Constituindo-se a categoria trabalho como um conflito insistente entre os interlocutores, de modo que este artigo, utilizando a técnica brainstorm, tem como objetivo, após perceber a demanda existente em determinado contexto, lançar mão das competências e potencialidades dos interlocutores para resolução dialógica da situação-problema, para um avançar dialético permanente, a fim de transformar realidades, com base nos seus sonhos, obtendo vantagens cumulativas.

Tendo a categoria trabalho como um conflito a ser resolvido pelos interlocutores com vista a uma vida digna, tomamos alguns passos para este percurso rumo a este objetivo. Incialmente propomos fazer um exercício de introspecção a partir da máxima "Conhece-te a ti mesmo", para perceberem suas potencialidades e talentos, habilidade e competências, para fazerem frente à demanda identificada, ou seja, o trabalho.

Para encaminhamentos a esta demanda e considerando as características do contexto da pesquisa e a urgência dos interlocutores, aplicamos a técnica brainstorm, pelo alcance e capacidade de focar e pensar soluções para um determinado tema, num curto período de tempo com uma abordagem dialógica, presando pela negociação, promovendo a autonomia em espaço onde as diferenças são respeitadas e a criatividade, valorizada.

Aplicado o exercício de introspecção e a técnica brainstorm, identificamos um aspecto preponderante como resolução para o conflito trabalho, a formação continuada ao longo da vida. Em seguida, lançamos mão de um objeto artístico para reflexão sobre o 
valor dos objetivos para cada um ou coletividade. Nesse sentindo, apreciamos a obra de arte "O farol", de Anita Malfatti. Nele pudemos perceber a EJA como elemento que faz parte deste caminhar dos interlocutores para a realização de seus sonhos.

Compreende-se, neste caso, que a escola oferta oportunidades aos interlocutores para realizarem tarefas que os levam aos seus objetivos, pois lhes garante capacidade técnica e consciência da realidade que deve ser tomada pela totalidade e da relação de suas partes que a compõe. Que esta estrutura deve ser ofertada através de políticas para amenizar efeitos nocivos às populações em estado de vulnerabilidade, que seja democrática com fins de que todos participem e os laços na comunidade sejam fortalecidos. Fica demonstrado neste artigo que o acesso à EJA garante vantagens cumulativas, inclusive o acesso ao emprego, além de outros benefícios.

Por fim, tratamos da capacidade de sonhar, de imaginar. Os conceitos abordados como o inédito viável e o potencialmente possível nos fazem acreditar que podemos alcançar o impossível e de sermos o que desejarmos. Logo, de que as nossas percepções podem se alargar, que nossa capacidade criativa pode tomar dimensões infinitas, pois somos seres em constante processo exponencialmente progressivo, posto que inacabados.

\section{Caracterização metodológica da pesquisa}

Diante da demanda exposta pelos interlocutores, após discussões sobre os motivos que os levaram à EJA e saber o contexto em que se encontravam, quisemos saber também de seus sonhos. A partir destas reflexões, apresentou-se a nós a demanda do trabalho como um desafio a ser solucionado. Portanto, o que veremos a seguir, concentra-se na resolução desta situação-problema emersa das discussões em grupos a partir de rodas de conversa e círculo de cultura.

Para localização do leitor, apresentamos sinteticamente as discussões do primeiro encontro (Quadro 1), realizado por meio de roda de conversa, demonstrando os motivos dos interlocutores de terem desistido dos estudos; a realidade em que se encontram; e os sonhos que desejam alcançar. 
Quadro 1 - Síntese do primeiro encontro.

\begin{tabular}{|c|c|c|c|c|}
\hline Nome & Idade & $\begin{array}{c}\text { Principal } \\
\text { motivo pelo } \\
\text { qual inter- } \\
\text { romperam } \\
\text { os estudos }\end{array}$ & $\begin{array}{c}\text { Ocupação } \\
\text { atual }\end{array}$ & $\begin{array}{c}\text { Principal motivo } \\
\text { pelo qual voltaram } \\
\text { a estudar }\end{array}$ \\
\hline Silva & 59 anos & Trabalho & Mecânico & $\begin{array}{l}\text { Aprender a ler e a } \\
\text { escrever }\end{array}$ \\
\hline Ferreira & 27 anos & $\begin{array}{l}\text { Separação } \\
\text { dos pais }\end{array}$ & $\begin{array}{l}\text { Sem ocupa- } \\
\text { ção }\end{array}$ & Trabalhar \\
\hline Pereira & 42 anos & Trabalho & $\begin{array}{l}\text { Sem ocupa- } \\
\text { ção }\end{array}$ & Trabalhar \\
\hline Alves & 40 anos & Trabalho & $\begin{array}{l}\text { Sem ocupa- } \\
\text { ção }\end{array}$ & Trabalhar \\
\hline Morais & 29 anos & Trabalho & $\begin{array}{l}\text { Sem ocupa- } \\
\text { ção }\end{array}$ & Trabalhar \\
\hline Costa & 34 anos & Trabalho & $\begin{array}{l}\text { Ajudante de } \\
\text { pedreiro }\end{array}$ & $\begin{array}{l}\text { Melhores oportuni- } \\
\text { dades de trabalho }\end{array}$ \\
\hline Nunes & 45 anos & Trabalho & $\begin{array}{l}\text { Pintor de } \\
\text { casas }\end{array}$ & $\begin{array}{l}\text { Melhores oportuni- } \\
\text { dades de trabalho }\end{array}$ \\
\hline Sousa & 53 anos & $\begin{array}{l}\text { Inacessibili- } \\
\text { dade }\end{array}$ & Diarista & $\begin{array}{l}\text { Melhores oportuni- } \\
\text { dades de trabalho }\end{array}$ \\
\hline Danta & 52 anos & Trabalho & $\begin{array}{l}\text { Dona de } \\
\text { casa }\end{array}$ & $\begin{array}{l}\text { Aprender a ler e a } \\
\text { escrever }\end{array}$ \\
\hline Monteiro & 54 anos & Casamento & $\begin{array}{l}\text { Dona de } \\
\text { casa }\end{array}$ & $\begin{array}{l}\text { Aprender a ler e a } \\
\text { escrever }\end{array}$ \\
\hline Santos & 37 anos & $\begin{array}{l}\text { Não houve } \\
\text { interrupção }\end{array}$ & $\begin{array}{l}\text { Professora } \\
\text { da EJA }\end{array}$ & $\begin{array}{l}\text { Aperfeiçoar-se na } \\
\text { docência }\end{array}$ \\
\hline
\end{tabular}

Fonte: Dados da pesquisa (2019).

No segundo encontro, pretendemos saber dos interlocutores, a partir das discussões do encontro anterior, os temas geradores. Para este fim, realizamos um círculo de cultura, em que cada participante sintetizasse o primeiro encontro em três palavras representativas. Entre as palavras constavam escola, trabalho e paz, propositalmente selecionadas para serem os referenciais, visto que condensavam as discussões, sendo as demais relacionadas a estas 
três. As outras palavras foram: oportunidade, dedicação, sonhos, sala, união, amor, respeito e acreditar.

A partir dos encontros anteriores, percebemos os motivos de os interlocutores terem desistido de estudar foi devido ao trabalho e, exatamente por causa deste, que agora adultos voltaram a estudar. Portanto, o trabalho constituía-se como um conflito a ser resolvido, visto que dentre seus objetivos na EJA destacam-se: aperfeiçoar-se no trabalho; ter melhores oportunidade de trabalho; e trabalhar. Ou seja, alguns ali encontravam-se sem ocupação à procura de trabalho, ou exercendo funções incompatíveis com sua capacidade física, ou ainda conflitantes com seus sonhos. Mostrando-se o trabalho como conflito urgente, pois muito dos interlocutores estavam sem fonte de renda, desempregados ou em subempregos.

Delineada a questão principal, a técnica utilizada para auxiliar na resolução do conflito foi o brainstorm: "que significa 'tempestade mental'. (...) Tem por objetivo a exploração das várias ideias, estimulando o raciocínio criativo, de forma a obtermos as melhores ideias e soluções num curto período de tempo, focalizando determinado assunto" (NUNES, 2019, p. 64).

Assim, os três grupos, formados com até quatro pessoas, lançaram mão do brainstorm com a intenção de fazer apontamentos para a resolução do conflito apresentado pelos interlocutores, o trabalho, em sua face mais perversa: o desemprego, o subemprego e a falta de fonte de renda.

Antes, no entanto, fez-se necessário abordarmos questões sobre as potencialidades frente a esta demanda apresentada. Nesse sentido, utilizamos para reflexão a máxima "Conhece-te a ti mesmo" para deles próprios terem as possíveis soluções. Posteriormente ao brainstorm, expomos um objeto artístico para dar seguimento às reflexões até o momento abordadas. Neste caso, utilizamos a obra de Anita Malfatti, "O farol”, de 1915.

Mais adiante fizemos uso de outros dois objetos artísticos, agora através da música e da literatura, por meio do poema "Das utopias", de Mario Quintana, e da música de Tom Jobim com Chi- 
co Buarque, "Imagina". Estas duas obras de arte mostram que os sonhos são possíveis de serem realizados e que este caminho é perpétuo, bastando assegurar-se do que diz Freire (2015) do "inédito viável" e de Galtung (2003) do "potencialmente possível". Observados os artistas e os teóricos, podemos alcançar e realizar o até então impossível, o que era sonho, o que era mágico, acumulando vantagens cumulativas.

\section{Diante das demandas: potencialidade e talentos}

Os interlocutores possuíam um conflito representado pela categoria trabalho, que precisavam resolver. Um dos caminhos possíveis seria primeiramente um processo reflexivo sobre autoconhecimento. Nesse sentido, expusemos a assertiva "conhece-te a ti mesmo", tendo em visto os sonhos e os caminhos para alcançá-los. Para esta prática, consideramos as motivações pedagógicas e éticas do Programa Abrindo Espaços da Unesco (NOLETO, 2008), que "materializa um dos fundamentos da cultura de paz: estimular a convivência entre grupos diferentes e favorecer a resolução de conflitos pela via da negociação" (p. 09).

Para que a ação exposta por Noleto (2008) tomasse corpo e ganhasse movimento, alguns critérios foram seguidos como o "mapeamento prévio das demandas e dos talentos nas escolas e na comunidade" (p. 61). Assim:

[...] Além de oportunidades de experimentar e desenvolver talentos e aprendizagens - encontros e relacionamentos sobre novos parâmetros. É desse modo que se redefinem prioridades, ampliam-se as percepções da realidade e se reforçam os valores da cultura da paz. (NOLETO, 2008, p. 64).

São condições que oportunizam o "desenvolvimento do potencial dos jovens, ao mesmo tempo que lhes assegurem possibilidades de se inserir de forma produtiva e criativa na sociedade" (NOLETO, 2008, p. 54). As demandas se resolvidas numa perspectiva em que os envolvidos assumam e sejam a eles garantidos o protagonismo, além de resolverem questões pertinentes ao dia-a-dia, 
também contribuem para o "desenvolvimento de competências e habilidades necessárias ao mundo do trabalho e à vida em sociedade, com ênfase no aprender a ser e no aprender a conviver" (p. 60). Contribuindo, inclusive, para a superação de tantos infortúnios que afligem os mais pobres, os mais vulneráveis.

Sustenta também o processo de autoconhecimento o historiador Harari (2018) que aconselha: "você terá de trabalhar muito duro para conhecer melhor seu sistema operacional. Para saber quem você é, e o que deseja da vida. Este é o mais antigo conselho registrado: conheça a si mesmo" (p. 329). Aqueles que negarem tal tarefa, Harari (2018) alerta que outros estão fazendo aquilo que deveria ser sua necessidade mais urgente. Governos e grandes empresas "estão todos correndo para hackear você" (p. 329). Portanto, para "manter algum controle sobre sua existência pessoal e o futuro de sua vida, terá de correr mais rápido que os algoritmos" (p. 330). Frente a este contexto, faz-se importante saber "de que tipo de habilidade ele ou ela vai precisar para conseguir um emprego, compreender o que está acontecendo a sua volta e percorrer o labirinto da vida?” (HARARI, 2018, p. 319).

Para Noleto (2008), qualquer que seja a formação dos indivíduos, estes devem desenvolver a capacidade de "interagir com o conhecimento, o mundo e seus pares de maneira consciente e crítica, a partir dos paradigmas do respeito às diferenças e da solidariedade" (p. 30).

Feita a reflexão introdutória sobre o autoconhecimento, que rememorou as habilidades e sonhos dos interlocutores para em seguida ser pensado soluções para o conflito, realizou-se o brainstorm. Nesse sentido, formaram-se três grupos de três e quatro componentes, para que, segundo a proposta do brainstorm, elencassem ideias para a resolução da situação-problema. Pelo engajamento dos participantes e a força que tomou a dinâmica, os conselhos foram transcritos, a seguir, na integralidade, valorizando o dito dos interlocutores e por demonstrar riquezas de ideias, que podem contribuir com os que tiverem contato com elas, colaborando com aqueles que se encontram em situações semelhantes. 


\section{Do grupo 1 emergiram os seguintes conselhos:}

No nosso grupo, primeiro foi estudar. Por que estudar? Porque é o início de tudo. Temos que estudar.

Oportunidades. O colega aqui deu exemplo do amigo dele, que tem um diploma... o colega dele tem curso, tem certificado e não arrumou nenhum emprego. Chega nos lugares e perguntam se tem experiência. Então, oportunidade.

Correr atrás. Por que correr atrás? Porque se a pessoa ficar parado... "tenho o diploma, tenho certificado, mas eu não vou procurar", então o serviço não vai chegar me chamando para ir.

Dinheiro. Acho que todo mundo precisa de dinheiro. Pra começar. Se você for pra faculdade, pra tirar sua xerox. Pra quem vem de escola de moto, pra pagar gasolina. Tudo isso envolve dinheiro. Não tem jeito.

Qualificação. Porque você fez um curso e ali parou. Não! Você precisa se qualificar. Porque quem vai se qualificando vai arrumando serviço, tomando suas oportunidades. Você vai ficando pra trás, então você não pode parar não, tá.

Dedicação. Tudo que for fazer tem que ter dedicação. Tem pessoa que fala assim, "mas não tenho tempo". Mas gente, a gente tem que se dedicar. Se você não tiver o foco. Aqui nós colocamos o foco, não colocamos? (Colocou). Se você não tiver foco, um objetivo. Se você não focar e tiver objetivo, tá, vocês não vão conseguir o resto, não. Tem que focar, ter dedicação. Não adianta só falar que eu quero. Tem que correr atrás e se dedicar pra conseguir. (Grupo 1, apresentado por Santos).

\section{Do grupo 2 os apontamentos foram:}

Bom, aqui tem um ponto, não desistir. Porque quando a pessoa tem um objetivo, precisa ser corajoso. Correr atrás. Então se a pessoa é desanimada e desiste, não vai alcançar. No segundo, colocamos ser persistente. Se você não insistir, muitas vezes a pessoa vai num certo local de emprego, de vaga de emprego, "não aqui já tá preenchido, nós não estamos precisando". Ali ele já vai desanimando já vai ficando pra trás. "Tá tão difícil", colocando barreiras e dificuldades. Tem que ser persistente. Correr atrás daquilo que você quer alcançar.

Se qualificar. Nós sabemos: para você possa arrumar um bom emprego, você precisa se atualizar. Se você não se qualificar naquilo que você quer ou outras coisas mais, você nunca vai encontrar uma vaga de emprego...

Ser insistente. É praticamente o que foi citado mais lá na frente. Tá sempre insistindo. 
Foi em um lugar, onviu um não, vai de novo, quem sabe aquela pessoa devido de tanto você ir vai falar "poxa esse cara realmente ele quer. Vou dar uma oportunidade pra ele". Devido a insistência daquela pessoa, acaba aquela pessoa se compadecendo pela motivação dele, acaba dando oportunidade. Ali, como já aconteceu, já vi caso de a pessoa ir duas, três vezes, ouviu um não, ele voltou pra trás e conversou com alguém de lá de dentro da empresa. Aquela pessoa conversou com o gerente e acabou dando oportunidade e ele tá até hoje, já vai fazer três anos. Então a sua insistência é muito bom. Aqui nós colocamos assim não desistir. Praticamente foi o que eu falei lá atrás né. Tem pessoa que desiste fácil devido na primeira vez ouvir um não. E aí, vai num outro, ouvi um não. E aí já começa a ficar mole. Não quer mais correr atrás. Então é isso aí.

Saber ouvir. Muitas vezes a pessoa é impaciente. Não tem tempo para ouvir. Muitas vezes a empresa tem umas certas normas, né. Muitos requisitos e a pessoa fica muito impaciente. Às vezes você não quer ouvir um conselho de outro e de outra. E acaba, devido a falta de paciência, ele acaba perdendo várias oportunidades. Hoje em dia para você se permanecer no emprego você tem que ter sabedoria, e atenção e paciência. Se você não é uma pessoa muito paciente o serviço não vai te servir. Porque tudo exige um pouquinho de paciência.

Buscar solução. (Danta: é estudar rapaz.) Estudar. Como a professora (Santos) falou. Primeiro lugar antes de vocês correr atrás de qualquer coisa, buscar sabedoria e a sabedoria vem através dos estudos. Ai quando você estuda, passa a ter bastante conbecimento você vai tendo noção do que você pode correr atrás e alcançar alguma coisa. Então, em primeiro lugar, o estudo.

Pensar sempre positivo. Tem pessoas que pensam muito negativo. "ah, não vou correr atrás daquilo não porque é muito difícil, exige muito da gente". Ai começa a pensar somente negativo, negativo. E o tempo passa e ele continua pra trás. É importante pensar sempre positivo.

Sonbar sempre alto. Tem pessoa que nunca pensa em ser alguém mais alto, pensa só nas coisas baixas. "Ah não, minha capacidade só é de colocar... limpar o chão". E ali, só se dedica àquilo dali. Pensa só em coisas baixas e ali nunca muda a vida dele. É sempre naquilo dali.

Tenha sempre mais de uma profissão. Eu, por exemplo, só trabalbei na área de pintura. São seis meses trabalhando e seis meses sossegado em casa. (risos). Seis meses no verão tô lá ralando pra caramba. Tá bom demais. Trabalho seis meses, enchendo a barriga e depois descansa mais seis, que é o inverno. Então, quando você tem mais de uma profissão, você nunca fica parado. Quando não tá bom, tem a outra... (Apresentado por Nunes, Grupo 2).

Do grupo 3 sugiram a ideias: 
A Monteiro falou que fazer um curso pra trabalhar é importante. (Monteiro: que para seguir uma profissão você tem que estudar, fazer um curso) (Madson: e o segundo?).

Para seguir em frente. Igual tava falando seguir em frente. (Madson: seguir em frente significa o quê?) Correr atrás, ser persistente.

O Alves falou fazer uma faculdade para veterinária e estudar.

(Madson: e o terceiro?) Seu Pereira era estudar pra trabalhar em máquina pesada (Madson: muito bem. E o quarto) O quarto aqui... foco, estudo, passar de ano, passar no ENCCEJA, estudar, estudar e estudar (Madson: muito bem).

Preciso de dinheiro (risos) foco, carinho e respeito pela profissão (Madson: muito bom) (palmas) (Grupo 3, apresentando por Ferreira).

Após a exposição, pode-se verificar que dentre os conselhos destacam-se palavras que convergem para a formação, que é contínua, permanente, na crença na formação ao longo da vida e dos benefícios decorrentes da formação continuada. Portanto, vale destacar que eles já fazem e estão vivenciando a formação através da modalidade de ensino EJA, como "estudar", "qualificação", "tenha mais de uma profissão", "fazer um curso".

A beleza daquilo que se poderia facilmente classificar como sabedoria, estes conselhos convergem para a liberdade, para a boniteza da vida em poder conviver com dignidade com os pares, com os familiares. Também de não se deixar abater pelo desânimo tão comum àqueles que estão desempregados ou são inteiramente dependentes financeiramente de terceiros. São fortes. Estes conselhos são destas pessoas, de sobreviventes. De lutadores que pelejam pela vida todos os dias em condições desfavoráveis e assimétricas, tanto temporais como materiais. Por isso mesmo as palavras tão presentes como "correr atrás", "pensar sempre positivo" "ser insistente", "não desistir", "ser persistente".

Possuem objetivos e, estes mais delineados, sabem onde se encontram e em que condições. Percebem que a caminhada pode ser dura, mas não impossível, porque recomenda-se "sonhar sempre alto" e "buscar solução" não esquecendo da "dedicação". Tendo que ter "oportunidade" e "dinheiro". 
Os sonhos são latentes e servem como guia para o avançar, para "seguir em frente". Portanto, nesse fazer e pensar que vão chegando, vão avançado, vão sendo mais gente, vão se constituindo, se formando em ser mais, porque mais ricos na humanidade, e, portanto, mais criativos, mais culturais. Vão se revestindo de mais beleza, de robustez, de possibilidades mais estendidas, de competências mais alargadas. É preciso "saber ouvir".

\section{Os objetivos como farol que orienta o percurso}

O livro "Alice no país das maravilhas", de Lewis Carrol, contém uma passagem famosa que trata exatamente de saber onde se quer ir para que se tome o caminho, pois do contrário, qualquer direção serve e assim torna-se fácil se perder, com gastos desnecessários de energia e de tempo. Feito a escolha, este caminho só faz sentido se percorrido envolto de liberdade e de ser mais. Um caminho que cada um deve percorrer na autonomia, da vontade sua e não de terceiros, tendo em vista a colaboração e responsabilidade com os outros e o meio no qual vive.

Tendo os objetivos apontados, resta saber qual caminho tomar. Os objetivos traçados pelos interlocutores foram arrumar um emprego, ascender profissionalmente, ter melhores condições de trabalho e outros que se assemelham à independência financeira e à qualidade de vida. Objetivos que reflete outras realidades da EJA pois, conforme o documento da UNESCO (2016, p. 98), " $80 \%$ e 90\% dos adultos que participam de programas de Aprendizagem e Educação de Adultos (AEA) relataram fazê-lo por razões relacionadas ao trabalho, ou seja, para obter um emprego, manter um emprego, ser promovido ou mudar para um emprego melhor".

Sabendo dos objetivos a que se deseja alcançar mais seguros se tornam os viajantes desta aventura. Para a compreensão de que os objetivos são o foco a que se deve mirar, lançou-se mão de um objeto artístico, "O farol", de Anita Malfatti (Figura 01). Exposta aos interlocutores, puderam conjecturar sobre os sentidos possíveis da obra tendo em vista as discussões anteriores. 


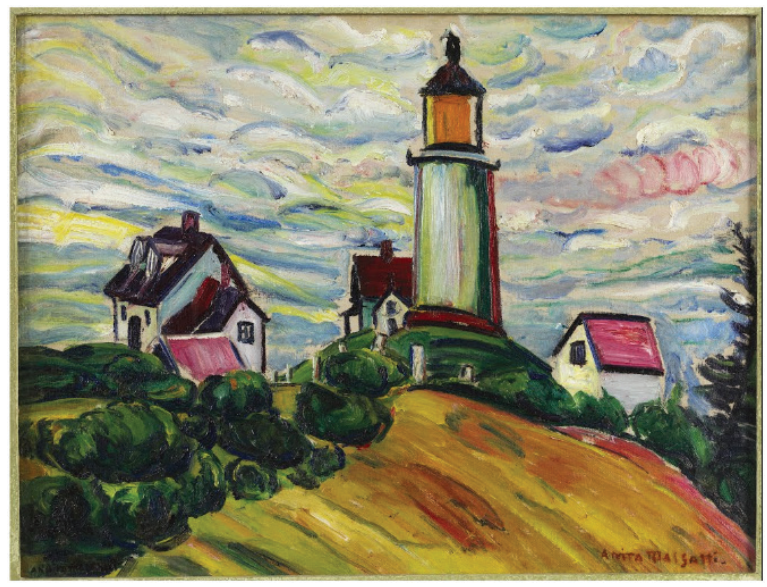

Figura 1: O farol (Anita Malfatti).

Fonte: https://artsandculture.google.com/asset/o-farol/IAG7LTjqF5L-

Qxw?hl=pt-BR

Inicialmente os participantes levantaram questões sobre aspectos visuais da pintura e divagaram sobre outras possibilidades como comparações e alguns significados. "Aíe ú farol. Bom, pelo que eu conheç, um farol na beira do mar" (Nunes). "Eu achei parecido com um" (Monteiro). "Parecendo umas casas no meio de uma serra" (Sousa). "Tipo interior" (Nunes). "Tá parecendo com uma chaminé" (Pereira). "Não. Tá parecendo com uma igreja também (Nunes).

Passando por esse processo de maturação colaborativa, os participantes começaram a formular proposições sobre a obra de Anita Malfatti. "Pros barcos ver, as embarcações ver. Que em algum lugar tem terra" (Ferreira). "Tipo uma sinalização" (Danta). O percurso não é retilíneo e há percalços. "Dá pra entender que tá numa serra, num morro" (Monteiro). "Vai chover, porque tá quase" (Ferreira). O tempo pode estar ruim, o acesso pode não ser fácil, mas o farol está lá.

As percepções tomaram uma ascendência e as proposições foram tomando formas mais abrangentes e com níveis de complexidade maiores. "Quantas ideias nós num teve hoje. Quantas coisas aprendemos com os outros. Mesmo assim é o farol. O farol clareia. Nos clareou a mente. Cada aula dessa pra nós é uma novidade" (Silva). 
Para inquiri-los, problematizou-se dos sonhos, dos objetivos que podem ser um farol. De maneira que o fazer tenha como base esses objetivos, esses sonhos. Veja-se uma das respostas: "Se você tem um sonho, tem um objetivo, você vai ficar parado? Vai correr atrás. A luz. é o teu sonho. Agora você tem que correr atrás pra você alcançar e realizar. Se você não correr atrás, se esforçar, fazer um esforço pra correr atrás você não vai conseguir" (Nunes).

O farol ajuda em qual sentido? "Pra guiar" (Todos). "Pra chegar lá no alto" (Monteiro).

Eu acho que agora que a frase que você colocou no começo fez sentido. 'Conhece-te a ti mesmo', você tem que conhecer o que você quer e quais são os seus sonhos, seu objetivo. Foi nesse sentido, não foi? Para você saber onde que vai chegar, onde você quer chegar. Então você tem que se conhecer, saber pra onde você vai. Se você sai sem saber a direção, então não vai pra lugar nenhum. Então você tem que focar num objetivo. Tem que parar e pensar: o que é que eu quero? Pra onde eu vou? (Santos).

Diante do exposto, fica a lição de que a frase "conhece-te a ti mesmo" envolve também saber o que se quer, de estabelecer os objetivos e tê-los como um farol que sinalizará para ninguém se perder. "Tem que tá mirando lá na frente" (Santos). "Eu não posso parar de sonhar, vai que eu realizo" (Sousa).

Eles todos se encontram em um mesmo caminho, estão na EJA. O objetivo da educação para jovens e adultos "é equipar as pessoas com as capacidades necessárias para que exerçam e realizem seus direitos e assumam controle de seus destinos" (UNESCO, 2016, p. 148). A partir do alcance da "equidade na alfabetização e na aquisição de competências básicas” (p. 33).

Compreendendo este processo, os sujeitos percebem que tais habilidades e competências vão se enriquecendo num acumular-se. De modo que a aprendizagem ao longo da vida tem "potencial influência sobre outras áreas da vida dos indivíduos, com a família, a saúde e a participação social" (UNESCO, 2016, p. 31). Os efeitos da educação "incluem o uso de mais eficaz dos serviços de 
saúde, estilos de vida mais saudáveis, melhores ambientes de trabalho e níveis mais baixos de estresse" (p. 70).

Portanto, a formação ao longo da vida reflete não só numa possível geração de renda, numa ascensão salarial ou mesmo na obtenção de recolocação no mercado de trabalho, mas também noutros aspectos da vida dos sujeitos, tal como melhor qualidade de vida. Estes benefícios são exponencialmente progressivos e seus reflexos incluem “a viver mais e melhor" (UNESCO, 2016, p. 71).

A EJA é um espaço no qual se ensina e se aprende e qualquer espaço que se pretende assim deve cultivar a emancipação dos sujeitos, através da problematização, de modo a instigar a todos a construírem o conhecimento, considerando a realidade material e histórica, pois:

[...] Quanto mais se problematizam os educandos, como seres no mundo com o mundo, tanto mais se sentirão desafiados. Tão mais desafiados, quanto mais obrigados a responder ao desafio (...) a compreensão resultante tende a tornar-se crescentemente crítica, por isso, cada vez mais desalienada. (FREIRE, 2015, p. 98).

Dizendo ainda: "pedagogia que faça da opressão e de suas causas objeto da reflexão dos oprimidos, de que resultará o seu engajamento necessário na luta por sua libertação, em que esta pedagogia se fará e refará" (FREIRE, 2015, p. 43). De acordo com Freire (2015), "humanização e desumanização, dentro da história, num contexto real, concreto, objetivo, são possibilidades dos homens como seres inconclusos e conscientes de sua inconclusão" (p. 40). Embora ambas sejam possibilidades, é a humanização "que chamamos de vocação dos homens" (p. 40). Da mesma forma que a humanização acontece num processo dialético de avançar, este ir em frente acontece de tal modo que a libertação de si é também a libertação do outro. "Quando os oprimidos, ao buscarem recuperar sua humanidade, que é uma forma de criá-la, não se sentem idealisticamente opressores, nem se tornam, de fato, opressores dos opressores, mas restauradores da humanidade de ambos" (p. 41). 
Os alunos da EJA, ao traçarem objetivos como melhores condições de vida e de trabalho, apontam para uma direção de humanização, de liberdade, de autonomia. Inicialmente pode parecer ainda turvo o caminho, mas conforme avançam, torna-se mais delineado e potente. Por isso, fazer como Freire (2015) recomenda: "os oprimidos, nos vários momentos de sua libertação, precisam reconhecer-se como homens, na sua vocação ontológica e histórica de ser mais" (p. 72). Posto que a liberdade não é algo dado, pronto e acabado, é dialética. Para Freire (2015), a liberdade é uma conquista, "exige uma permanente busca. Busca permanente que só existe no ato responsável de quem a faz" (p. 46). Processo que é de conscientização, em que "no momento em que a percepção crítica se instaura, na ação mesma, se desenvolve um clima de esperança e confiança que leva os homens a se empenharem na superação das "situações limites"' (p. 126). Essa mesma ação requer planejamento.

[...] Já vimos que não há prática sem avaliação. Mas a prática exige também seu planejamento. Planejar a prática significa ter uma ideia clara dos objetivos que queremos alcançar com ela. Significa ter um conhecimento das condições em que vamos atuar, dos instrumentos e dos meios de que dispomos. Planejar a prática significa também saber com quem contamos para executá-la. Planejar significa prever os prazos, os diferentes momentos da ação que deve estar sempre sendo avaliada. Podemos planejar a curto prazo, a médio prazo e a longo prazo. Às vezes a avaliação nos ensina que, se os objetivos que tínhamos eram corretos, os meios que escolhemos não eram os melhores. Às vezes, percebemos também, através da prática da avaliação, que os prazos que havíamos determinado não correspondiam às nossas reais possibilidades. (FREIRE, 1989, p. 47).

Assim, é preciso sistematizar as ações de modo que se garanta, de acordo com Freire (1989), organização e que para ter tal característica é necessário adotar disciplina, ordem, decisão, objetivos, tarefas a cumprir e contas a prestar. Por isso em Freire (1989), além da unidade, disciplina, trabalho e vigilância, também a importância do planejamento nessas ações. 


\section{EJA e seus benefícios cumulativos}

Os motivos dos interlocutores de estarem na EJA estão estreitamente relacionados ao trabalho, de melhorar as condições de trabalho ou mesmo de arrumar um emprego ou ainda de ter uma renda para ajudarem a si e seus próximos como os familiares - filhos e netos principalmente. Pode-se afirmar que estão em sentido certo, visto que a EJA, comprovadamente, traz benefícios para os sujeitos nos seus afazeres. Para o sujeito, os benefícios da EJA são diversos, que vão desde aumento da renda até maior satisfação no trabalho, conforme diz o Terceiro Relatório Global sobre Aprendizagem e Educação de Adultos:

[...] Renda; mais indivíduos são empregáveis; mais pessoas têm acesso ao mercado de trabalho; mais pessoas podem progredir ao longo da carreira; mais indivíduos são capazes de mudar de emprego ou até mesmo de ocupação; os empregados ficam satisfeitos com seus empregos; os indivíduos são mais saudáveis e têm maior sensação de bem-estar. (UNESCO, 2016, p. 89).

Esses benefícios levam a outros, pois “indivíduos que estão satisfeitos com seus empregos têm maior compromisso e dedicação a suas organizações" (UNESCO, 2016, p. 90). Em consequência, "trabalhadores mais comprometidos também são propensos a dedicar sua energia emocional e criativa para inovar e produzir bens e serviços de maior qualidade" (p. 90).

A EJA, além do trabalho, reflete positivamente também na saúde dos sujeitos. Fato que poderia ter evitado o ocorrido com Alves: "Eu mexia com trabalho de pintura. Numa lojinha. Eu acidentei. Tem três anos agora que acidentei"; e com o Morais: "Atualmente estou desempregado. Faz uns onze meses que eu adoeci, fiz. uma cirurgia". Destacam-se aqui situações de acidentes no trabalho e intervenções cirúrgicas, tendo que, em alguns casos, interromper suas funções e mesmo tendo que mudar de trabalho, diminuindo ainda mais as chances de avanços na profissão e aumento de renda.

Segundo o mesmo relatório da UNESCO (2016), a relação entre educação e saúde é inequívoca e bem estabelecida, pois indi- 
víduos mais escolarizados cuidam mais de si, resultando, coletivamente, em uma comunidade e sociedade mais saudável também. Ainda mais quando a idade avança, onde os cuidados consigo aumentam, visto que:

[...] À media que as pessoas fazem a transição para a vida adulta e envelhecem, elas precisam ser capazes de administrar a própria saúde, doenças e deficiências - e de seus dependentes. Isso requer conhecimento, habilidades, comportamentos e atitudes desenvolvidas não apenas por meio da educação e da aprendizagem inicial, mas durante toda a vida. (UNESCO, 2016, p. 68).

Os benefícios se retroalimentam. Indivíduos saudáveis produzem mais no trabalho e geram menos gastos com despesas hospitalares que, por sua vez, também geram maiores resultados de aprendizagem. Logo, uma boa saúde gera: "melhores resultados de aprendizagem devido a redução de faltas na educação; menos faltas no trabalho; maior capacidade de cumprir responsabilidades familiares e estar envolvido com a comunidade" (UNESCO, 2016, p. 69).

Quanto aos benefícios na comunidade, estes são expressivos e fundamentais: "A AEA [Aprendizagem e Educação de Adultos] ajuda os cidadãos a se tornarem mais altivos na sociedade civil e na vida política, mais tolerantes com a diversidade" (UNESCO, 2016, p. 107). Também a EJA “ajuda a promover a coesão e a integração social, aumentar a participação em atividades sociais e políticas e estimula a criação de comunidades de aprendizagem que podem responder a grandes desafios" (p. 107). Ou seja, a EJA contribui para a cultura de paz, pois "os programas de alfabetização ajudam a desenvolver valores democráticos, de coexistência pacífica e de solidariedade comunitária” (p. 110).

Nos relatos dos interlocutores alguns benefícios podem ser identificados. Interessante notar que as repercussões da EJA em suas vidas extrapolam o principal motivo pelo qual voltaram a estudar, isto é, o trabalho. No caso da Danta, ela disse já saber fazer sua lista de compras e a lista de contas a pagar. Habilidade que foi 
construída em sala de aula. Além da Danta, a Santos diz que todos têm avançado em habilidades básicas de Português e Matemática.

A EJA, além de espaço de aprendizagem, é também espaço de convivência. Veja-se o que diz a Monteiro: "eu tô me sentido bem. Cansada, mas às vezes quando chego aqui é tão bom. Você aprende. Você tem um problema, você conversa com uma pessoa, de repente... ameniza mais". Assim, a EJA também faz experimentar sensações que estão para além do material, mas em âmbito da subjetividade, da memória afetiva, pois é assim que agora se sente o Pereira, quando sua filha mostra o dever de casa e se emociona em ver as atividades realizadas, porque sabe que filhos e netos podem ter oportunidades melhores que as que ele teve quando criança.

Para o Silva, entrar em um fluxo que a sua família já vinha fazendo, pois de acordo com seu relato todos em sua casa estudam. Além de entrar na EJA, tenta influenciar seus amigos para seguir o mesmo caminho. Há também o aspecto da valorização e autoestima, pois quem faz EJA é bem-visto na comunidade e recebe incentivos dos mais próximos.

Para a Sousa, a EJA a possibilita sonhar, ter esperança em melhores condições de vida, espaço de aprendizagem e de outros caminhos a percorrer. Rumos mais felizes e mais leves, pois encontra-se já em idade que seu serviço exige energia que não pode mais conceder por muito mais tempo. Nesse sentido, também o Morais confia na EJA como meio para se alcançar níveis mais elevados de modo mais rápido, pois como ele mesmo diz, tudo é tão corrido. Para o Ferreira a EJA "tá sendo importante, porque sempre dando um passo pra frente... Seguir em frente, continuar vivendo".

O Ferreira, o Morais, a Sousa, o Silva, o Pereira, a Monteiro e a Santos são sujeitos que se comunicam com a EJA de modo singular, diverso. Todos os relatos informam experiências positivas e esperançosas que já percebem pequenas, mas significativas, mudanças benéficas em suas vidas e com as pessoas com quem se relacionam, portanto, na comunidade onde vivem. 


\section{Das utopias e o inédito viável: imagina}

$\mathrm{Na}$ perspectiva até o momento discutida, preste-se atenção ao que expressa Galtung (2003, p. 9):

[...] O espaço de ação de uma pessoa (P), em busca de uma saída para um conflito, num determinado ponto do espaço (E) e do tempo (T), em geral pode ser subdividido em três subzonas: o convencionalmente possível (CP), o potencialmente possível (PP), e o impossível (IM). P tenta CP e não encontra solução alguma. P não é muito criativo, entre outros motivos porque vive imerso numa cultura onde o mundo é visto como inflexível, governado por leis naturais ferrenhas e leis sociais garantidas por pulsos de ferro. P desiste, acreditando que PP não existe e que IM começa onde CP termina. Nem é preciso dizer que se a violência está contida em CP (e em geral está - a maioria dos povos do mundo já ouviu falar da violência e já aprendeu algo sobre ela, por mais inocentes que tenham sido em algum lugar do passado), e se CP é muito limitado e PP inexistente, então a violência surge como solução em primeira instância.

Para os que se encontram na EJA, ainda mais para alunos do primeiro segmento, os objetivos podem parecer distantes e talvez impossíveis de serem alcançados. Contudo, como já analisado, inicialmente os benefícios podem parecer poucos, mas neste avançar dialético vai se potencializando e ganhando velocidade e aquilo que parecia distante, agora se aproxima. O poema de Mario Quintana, "Das utopias", orienta este caminhar:

Se as coisas são inatingíveis... ora!

Não é motivo para não querê-las...

Que tristes os caminhos, se não fora

A mágica presença das estrelas (2005, p. 28)

Na concepção do Silva estes versos lembram que: "Você tem sempre que sonbar né. Você tem sempre querer uma coisa a mais. Você quer, mas nunca sabe se vai ter. (...). Você nunca deve deixar de sonhar. Tem que sonhar e terfé". Em tom de realismo a Monteiro recomenda: "Minha mãe diəzia "Sonhar não épecado. Sonhar é bom. Mas sonbar com o pé no chão"”. De igual modo o Silva emenda: "Se você sonhar e não correr atrás. Não adianta nada 
você querer uma coisa... sem força de vontade". A Santos reitera: "é ralando muito". É como diz a Monteiro: "é sonhar e ter vontade".

É preciso acreditar que é possível e extrapolar a barreira das limitações. Pode-se ser aquilo que se imagina. Por isso, é tão importante imaginar, sonhar. Quem sonha, quem imagina, já possui a centelha das possibilidades, uma característica essencialmente de humanização. Quem imagina, os caminhos tornam-se diversos e as possibilidades infinitas. Veja-se o que diz a música de Tom Jobim e Chico Buarque (2006):

Imagina

(...)

Abre a porta para a noite passar

E olha o sol da manhã

Olha a chuva

Olha a chuva, olha o sol

Olha o dia a lançar serpentinas

Serpentinas pelo céu

Sete fitas

Coloridas

Sete vias

Sete vidas

Avenidas para qualquer lugar

Imagina

Imagina

Sabe que o menino que passar debaixo do arco-íris vira moça, vira

A menina que cruzar de volta

$\mathrm{O}$ arco-íris rapidinho volta a ser rapaz

A menina que passou no arco era

$\mathrm{O}$ menino que passou no arco

E vai virar menina

Sobre a música o Silva conclui que: "imaginar quer dizer, sonhar". A Santos destacou: "eu gostei dessa parte, a avenida vai pra qualquer lugar. Sua imaginação pode ir pra qualquer lugar. (...). Então você pode imaginar o que você quiser". 
O Silva lembra de uma situação sobre si e sua colega:

Ela pensou que não era capaz de fazer o que ela já fez. Eu também nunca pensei que eu era capaz de chegar... Ela ((Monteiro)) também, dois, três dias atrás aí ela não queria nem abrir a boca pra ler uma palavra. Você viu o tanto que ela já expressou. $\mathrm{O}$ tanto que ela se soltou. Ela tá se conhecendo. Ela tá se descobrindo ela. (...). Onde? No EJA. Todos nós tá descobrindo uma coisa que nós não tinha. Tendo a oportunidade de conhecer. (...). É aquilo que você falou, uma coisa vai puxar outra. Falando com elas ali, lembrei do que nós conversamos ontem. Da capacidade de cada um. (...). Agora você imagina o Silva todo dia aqui na escola.

Tanto o poema de Mário Quintana quanto a música de Tom Jobim com Chico Buarque são objetos artísticos que levam a uma experiência estética. As reações a este poema e a esta música especificamente variam de acordo com o nível de percepção de cada um dos interlocutores. Houve aqueles que estranharam e aqueles que se mostraram mais familiarizados.

Para compreender os níveis de recepção a uma experiência estética, se de estranhamento ou de familiaridade, é necessário saber que existe a percepção consciente "que trabalha no sentido de eliminar uma série de elementos vistos como "perigosos" (DUARTE JÚNIOR, 1987, p. 68), empurrando-os para o inconsciente. Visto que o sensor da mente, o superego, "procura afastar da consciência todos os desejos, forças e emoções violentas e primitivas que nos habitam (...) que faz retornar ao inconsciente não só tais forças como todas as formas que as simbolizam” (p. 69). Significa que:

[...] A mente de superfície, ao elaborar o campo perceptivo, articula os elementos em formas mais perfeitas e também delimita a identidade dos objetos, tornando-os reconhecíveis e com volume. Já a percepção inconsciente não apenas capta elementos inarticulados como ainda pode fundir e justapor as formas dos objetos e as formas de suas partes, criando configurações ausentes de nossa realidade consciente, criando formas 'sem coisas'. (DUARTE JÚNIOR, 1987, p. 70). 
No momento da experiência estética há a disputa entre as duas percepções, consciente e inconsciente, e nisto consiste o prazer, visto que:

[...] O sentimento da beleza advém deste conflito de percepções. Advém do trabalho redobrado da mente de superfície que, buscando manter na consciência apenas os elementos não perigosos, constroem formas mais bem-acabadas e plenas com a finalidade de, por elas e nelas, prender a atenção. (DUARTE JÚNIOR, 1987, p. 71-2).

Observar também que existe o "feio por ultrapassado e o feio por novidade" (DUARTE JÚNIOR, 1987, p. 77-8). “O primeiro tipo ocorre quando (...) aqueles elementos inarticulados ali presentes se tornaram perceptíveis à mente de superfície e as obras deixaram de gerar tensão nos espectadores" (p. 78). No segundo, "quando uma nova proposta estética surge, ela traz em si novos elementos inarticulados" (p. 78), gerando uma "enorme tensão no espectador" (p. 78) "Desta maneira, eles são percebidos como perigosos e geram sentimentos profundos de ansiedade e culpa, que se travestem no sentimento do freio, fazendo com que o espectador se afaste da obra" (DUARTE JÚNIOR, 1987, p. 80).

Nesse sentido, na exposição desses objetos, respeitou o nível provável de percepção dos interlocutores, sem jamais subestimá-los (FREIRE, 2015). Neste caso, a experiência estética deu-se através de ajustes da proposta de sentidos a serem construídos pelos interlocutores, às vezes ficando em detalhes mais pontuais.

Os objetos artísticos tiveram como proposta reforçar e alargar a compreensão sobre as discussões propostas, tendo como princípio a problematização como movimento dialético para a construção da consciência, num movimento de inacabamento, sendo os sujeitos "inconclusos em e com uma realidade que, sendo histórica também, é igualmente inacabada” (FREIRE, 2015, p. 102). Processo este que "só se justifica na medida em que se dirige ao ser mais, à humanização” (p. 104). 
Elementos artísticos que possibilitam questionamentos que os interlocutores são impelidos a fazer a si e sobre a realidade, exigindo respostas tanto em nível intelectual quanto em nível de ação (FREIRE, 2015). Além de ajudar a saber em que nível de percepção os interlocutores percebem de si e da realidade, os objetos artísticos, a depender do grau de dificuldade, os participantes podem demonstrar, em caso extremo, de completa passividade, não tendo, então nada a dizer ou mesmo a nada se incomodar, como também inquietar-se. Por isso, "igualmente fundamental para sua preparação é a condição de não poderem ter as codificações, de um lado, seu núcleo temático demasiado explícito; de outro, demasiado enigmático” (p. 151).

Paulo Freire chama atenção para aquilo que ele denomina de "inédito viável", que é respeitar o nível de percepção dos interlocutores de modo que possam alcançar a síntese e também, metodologicamente, não perderem o foco, desinteressando-se caso pareça impossível de compreensão como também demasiado evidente. Nesse processo de descodificação, "cabe ao investigador, auxiliar desta, não apenas ouvir os indivíduos, mas desafiá-los cada vez mais, problematizando, de um lado, a situação existencial codificada e, de outro, as próprias respostas que vão dando aqueles no decorrer do diálogo" (FREIRE, 2015, p. 157).

Duarte Júnior e Paulo Freire discorrem sobre a tensão a que se dá o processo de construção da síntese, do avançar, da percepção para um e da consciência para outro, sendo os mecanismos para sua compreensão. Destas observações retiradas a partir destes autores é a necessidade de respeitar os níveis de percepção dos interlocutores, mas também perceber estes níveis de percepção como matéria para a própria análise e dela partir para o avançar, tal como Freire (1989, p. 17) explica:

[...] Estando num lado da rua, ninguém estará em seguida no outro, a não ser atravessando a rua. Se estou no lado de cá, não posso chegar ao lado de lá, partindo de lá, mas de cá. Assim também ocorre com a compreensão menos rigorosa, menos exata da realidade. Temos de respeitar os níveis de compreensão que os educandos - não importa quem sejam - estão tendo de sua própria realidade. 
Tão importante saber desses mecanismos para a própria ação entre alunos da EJA, como também na condição destes como interlocutores. Também na condição de pesquisador, Paulo Freire $(2015,1989)$ convida a fazer este movimento de ação e reflexão para que se alcance níveis mais elevados de consciência sobre si e a realidade, de modo que assim, a humanização vá se construindo e as mudanças na realidade vão se fazendo, com sentido.

\section{Considerações Finais}

Dos temas geradores trabalho, escola e paz, o trabalho constituiu-se como situação-problema para os interlocutores, tendo a escola como possibilidade de resolução deste conflito, em ação planejada que considera aspectos democráticos, ou seja, permeada pela cultura de paz. Este percurso considerou as demandas aqui representadas pela busca de emprego, melhores condições de trabalho e geração de renda, tendo em vista as potencialidades dos interlocutores, exigindo um autoconhecimento configurado na máxima "Conhece-te a ti mesmo". Também consideramos a metodologia com vista aos objetivos, considerando as estruturas e seus funcionamentos. Dessa forma, neste caminhar, garantir vantagens que são cumulativas, numa perspectiva criadora, que considere o potencialmente possível e o inédito viável.

Diante de uma demanda, conforme o percurso desta pesquisa, ficou evidente o quanto necessário é o fato de se estabelecer os objetivos que se quer alcançar. De outro modo, pode-se facilmente se perder com desperdício de energia e tempo. Portanto, é importante saber o que se quer para se ter minimamente controle sobre os rumos a tomar, os caminhos a percorrer. Sabendo onde se quer chegar, que objetivos alcançar, talentos e potencialidade são mobilizados além de outros recursos como os conhecimentos e habilidades técnicas. Ficou evidenciado que este percurso deve ser realizado numa perspectiva democrática em que o outro é valorizado e as diferenças são cultivadas, prezando pela negociação nas resoluções 
dos conflitos. Notou-se que este caminhar junto é mais vantajoso para o indivíduo e coletivamente mais democrático. Estes pontos levantados durante as discussões deste artigo, só pesam em significado se se tendo a compreensão do todo, ou seja, do contexto, e as relações de suas partes.

Com a técnica brainstorm, focamos no conflito que afligia os interlocutores. Para sua resolução, diversas sugestões apontaram para a formação, ou seja, estavam na EJA para melhorar suas condições de trabalho, para angariar vagas de trabalho e poder auxiliar filhos e netos. O brainstorm, além do exercício do diálogo, da negociação, busca a construção da autonomia, através de trabalho em grupo. Esta prática coletiva fortaleceu e confirmou os laços entre os envolvidos. Esta ação alcançou sucesso porque entre os interlocutores havia um objetivo comum, a resolução do conflito configurado pelo trabalho; fato que contribui para superação de diferenças, gerando solidariedade entre os participantes.

Nesse sentido, "O Farol”, como representação daquilo que se quer alcançar, ajudou na compreensão de que os objetivos são os guias de nossas ações. Foi assim que os interlocutores perceberam que a formação continuada ao longo da vida é uma prática que deve ser permanente, porque neste avançar, de prática e reflexão, em resolução de conflitos e superação de situações-limites, novos conhecimentos são construídos. Neste cumular, novas habilidades e competências são assumidas, fazendo com que o caminhar tome velocidade e ocorra o alargamento dos horizontes, e aquilo que incialmente parecia muito complexo, agora parece mais simples de execução, ou seja, o fazer guiado pela formação ao longo da vida amplia a liberdade dos sujeitos, ou seja, quanto mais conhecimento, mais liberdade se tem.

A dinâmica até aqui abordada deve ser realizada dentro de uma estrutura, pois de outro modo não seria possível. A educação básica é uma dessas estruturas na qual os interlocutores estão inseridos e fazendo uso. Estrutura que é resultado de políticas públicas que minimizam as desvantagens dos sujeitos em situação de vul- 
nerabilidade e possibilitam qualidade de vida. Sem estrutura, não há como realizar práticas como a de estudar na EJA, por exemplo. Fato que impossibilitaria alcançar os objetivos dos interlocutores cujo caminho perpassa pela formação continuada oferecida pela escola. Esta mesma estrutura garante um efeito retroativo, devido a transformação que estas mesmas estruturas permitem. São as capacidades que os sujeitos lançam mão para realizar suas tarefas. Além de democrática, garantindo maior sustentabilidade da rede de comunicação dos sujeitos, a prática dentro desta estrutura deve ser feita sistematicamente possibilitando melhores resultados. Portanto, as ações devem ser planejadas e assentada em confiança, para que o ambiente se torne colaborativo, de ajuda mútua.

Esse conjunto de fatores levam a vantagens cumulativas como maiores chances de emprego, com maior liberdade aos sujeitos e benefícios para a comunidade em que vivem. Num movimento dialético que considere o potencialmente possível, afinando a criatividade, expandido o poder de agente, tornando-se cada vez mais autônomo, com capacidade de imaginar e sonhar realidades melhores, mais justas, nas quais pode-se ser o que desejar. No avançar, possibilitado pela formação ao longo da vida, o mundo torna-se mais colorido, mais sonoro, os sabores mais diversos e tantas outras sensações permitidas quando se aumenta o nível de percepção e consciência da realidade.

\section{Referências}

BUARQUE, Chico. Carioca ao vivo. São Paulo: Tom Brasil, 2006. 2 discos.

DUARTE JÚNIOR, João-Francisco. O que é beleza. São Paulo: Editora Brasiliense, 1987.

FREIRE, Paulo. A importância do ato de ler: em três artigos que se complementam. São Paulo: Cortez, 1989.

FREIRE, Paulo. Pedagogia do oprimido. 59. ed. Rio de Janeiro: Paz e Terra, 2015. 
GALTUNG; Johan. Paz Cultural: Algumas Características. 2003. Disponível em: http://www.palasathena.org.br/arquivos/conteudos/Paz_Cultural_Johan_Galtung.pdf. Acesso em: 2 mar. 2020.

HARARI, Yuval Noah. 21 lições para o século 21. Tradução Paulo Geiger. São Paulo: Companhia das Letras, 2018.

NOLETO, Marlova Jovchelovitch. A construção da cultura de paz: dez anos de história. In: DISKIN, Lia; NOLETO, Marlova Jovchelovitch (Coord.). Cultura de paz: da reflexão à ação; balanço da Década Internacional da Promoção da Cultura de Paz e Não Violência em Benefício das Crianças do Mundo. Brasília: UNESCO; São Paulo: Associação Palas Athena, 2010

NUNES, Antônio Ozório. Como restaurar a paz nas escolas: um guia para educadores. São Paulo: Contexto, 2019.

QUINTANA, Mário. Espelho mágico. São Paulo: Globo, 2005.

UNESCO. Terceiro relatório global sobre aprendizagem e educação de adultos. Brasília: UNESCO, 2016. 